information for others to reproduce a study. However, we do not think that a particular journal's editorial style is relevant to the IACUC's deliberations.

Based on the above references, and the fact that there were no veterinary or other scientific concerns, we are in agreement with both Jones and the scientific members of the IACUC. We would vote to approve the protocol (potentially with clarifications in order to secure approval) without requiring duplicative pilot studies.

Lori R. Hill* and William B. Norton

The University of Texas M.D. Anderson Cancer

Center, Houston, TX, USA.

*e-mail:LRHill@mdanderson.org

Published online: 27 January 2020

https://doi.org/10.1038/s41684-019-0462-Z
References

1. Collins, F.S. and Tabak, L. A. Nature. 505 (7485). 612-13. (2014)

2. National Institutes of Health. Guidance: Rigor and Reproducibility in Grant Applications. https://grants.nih.gov/ policy/reproducibility/guidance.htm Accessed 10-16-19.

3. Institute for Laboratory Animal Research. Guide for the Care and Use of Laboratory Animals, 8th edition. (National Academies Press, Washington, D.C., USA, 2011).

4. NIH Grants Policy Statement. 4.1.1.2 Verification of IACUC Approval https://grants.nih.gov/grants/policy/nihgps/html5/ section_4/4.1.1_animal_welfare_requirements.htm Accessed $11 / 12 / 19$

\title{
Consider both sides
}

$\mathrm{n}$ this scenario, both the IACUC scientist and the researcher, Dr. Jones, have valid points to consider. Reproducibility of data is a concern, especially with complicated animal models, and should be carefully considered so that animals are used thoughtfully. It can be necessary to include large numbers of animals in study groups in order to arrive at scientifically valid results if there is significant variability due to inherent lack of model reproducibility.

As an IACUC member I would not approve a protocol simply because it was federally funded. Federal funding status alone does not automatically make a research project scientifically valid, though it is helpful to know that an external review body of scientific peers did consider the work to be worthy of financial support.
It is the IACUC's task to determine whether the particular research protocol submitted to their review is scientifically valid and of sufficient importance to validate use of animals, that it conforms to the 3R's principles, and whether appropriate alternatives exist that should be considered.

As a reviewer I would have some additional questions for Jones. Are these Category E studies or studies otherwise anticipated to cause significant pain or distress to the animals for which analgesia is warranted? If so, the impact to the animals on study is greater and should be considered carefully against the anticipated benefits of the research. Does she anticipate using large groups of animals due to variability? Have her results been consistent across multiple studies which would help support her own technique's internal reproducibility?

Since a previous pilot program was conducted, I agree that requesting Jones to repeat this work would be unnecessary and would not comply with the 3 R's, unless she has significantly changed her technique or approach. If Jones can show that her current technique is yielding useful data, I would agree with the other scientists on the IACUC and approve the protocol.

Melissa Haskell

Lab animal veterinarian and toxicologist, Boston, MA, USA.

e-mail:mhaskell@hotmail.com

Published online: 27 January 2020 https://doi.org/10.1038/s41684-019-0463-y 